\title{
Plantão Psicológico em Hospital Geral: Um Estudo Fenomenológico
}

\section{Psychological Service for Employees: A Phenomenological Survey}

\author{
Tatiana Hoffmann Palmieri* \& Vera Engler Cury \\ Pontifícia Universidade Católica de Campinas, Campinas, Brasil
}

\begin{abstract}
Resumo
Com o objetivo de compreender os desafios e potencialidades de um Serviço de Plantão Psicológico voltado aos funcionários de um Hospital Geral, foram entrevistados seis funcionários que vivenciaram esta modalidade de atendimento durante a fase de implantação. As entrevistas foram não-diretivas, e fez-se uma pergunta disparadora para estimular os depoimentos. Por meio de uma metodologia qualitativa, analisaram-se os depoimentos fenomenologicamente, partindo-se da divisão do tex to em unidades de significado, possibilitando a construção de uma compreensão psicológica acerca das vivências. Para cada depoimento foi elaborada uma síntese específica dos elementos do vivido. Esse material serviu para compor uma Síntese Geral que incluiu elementos comuns a todas as sínteses específicas. A riqueza dos depoimentos possibilitou algumas incursões para aprofundar os limites e as possibilidades encontradas na prática desta modalidade no contex to hospitalar. Palavras-chaves: Plantão psicológico em hospital geral; abordagem centrada na pessoa; prática psicológica clínica em instituição hospitalar.
\end{abstract}

\begin{abstract}
With the objective of understanding the challenges and potentials of a Psychological Service for employees in a General Hospital, six employees were interviewed whoexperiencedthis service during the implantation phase. The interviews were non-directive, and a starter question was made to stimulate the statements. Through a qualitative methodology, the statements were phenomenologically analyzed: starting of by breaking the text in units of meaning, to enablethe construction of a psychological understanding concerning the living experiences. For each statement a specific synthesis of the elements was elaborated. That material served to compose a General Synthesis that included elements common to all of the specific synthesis. The wealth of the statements enabledsome incursions to deepen the limits and the possibilities found in the practice of this modality in the hospital context.

Keywords: Psychological service in a general hospital; personcentered approach; clinical psychological practice in a hospital organization.
\end{abstract}

A modalidade de atendimento denominada de Plantão Psicológico, assemelha-se a experiência das «walk-in clinics», uma modalidade de clínica institucional, utilizada principalmente no EUA nas décadas de 70 e 80 , que visava um atendimento emergencial médico ou psicológico ao cliente, no momento em que havia a procura, tendo alcançado considerável abrangência na área da Saúde (Dyck \& Azim, 1983).

No Brasil, o Plantão Psicológico também é uma prática que tem sua origem essencialmente institucional e vem se ampliando e solidificando no âmbito da Psicologia Clínica. A sua base teórica foi fundamentalmente humanista e a maioria dos diversos contextos nos quais esta modalidade de atendimento foi difundida, teve como referência a proposta do Serviço de Aconselhamento Psicológico da Universidade de São Paulo (USP).

\footnotetext{
* Endereço para correspondência: Rua Dom José Paulo da Câmara, 715, Jd. Paraíso, Campinas, SP, 13100-027. Tel.: (19) 3386-1190 ou (19) 329246-2325. E-mail tataing@hotmail.com
}

Isso se deve ao fato de que o primeiro Serviço de Plantão Psicológico de que se tem registro no Brasil foi implantado no Instituto de Psicologia da USP (IPUSP), em 1969, mais especificamente no Setor de Aconselhamento Psicológico. Referir-se a este Serviço inevitavelmente remete à Abordagem Centrada na Pessoa, criada pelo psicólogo americano Carl Rogers e colaboradores que, a partir dos anos 50, têm influenciado fortemente os psicólogos humanistas no Brasil; sua influência nos EUA já era significativa antes disso (Eisenlohr, 1997).

$\mathrm{Na}$ mesma época, os plantonistas do SAP (Serviço de Aconselhamento Psicológico) do IPUSP sentiram necessidade de teorizar sobre o Plantão Psicológico, pois consideravam que esse tipo de atendimento possui em si mesmo uma verdadeira ajuda psicológica, e não se configura como uma preparação para um tratamento mais prolongado ou um substituto para o processo de triagem, comum nas Clínicas-Escolas (Eisenlohr, 1997).

Pereira (1999) afirma que há várias definições acerca do Plantão Psicológico que se distinguem conforme a abordagem teórica dos profissionais que trabalham com esta 
modalidade e também em função das circunstâncias vigentes no momento da implantação nas instituições e nos diferentes contextos nos quais o Plantão Psicológico é inserido. Isto se evidencia no Serviço de Plantão Psicológico da Pontifícia Universidade Católica de Campinas (PUC-Campinas), que além da Abordagem Centrada na Pessoa, inclui o referencial Cognitivista numa mesma modalidade de relação de ajuda Psicológica (Cury, 1999a).

Diante disso, Mahfoud (1987) aponta que o Plantão Psicológico deve ser delineado a partir de três vertentes: a da instituição que oferece o serviço, a do profissional disponível para o não-planejado e a do cliente que busca auxílio para suas necessidades emergentes.

Ressalta-se, contudo, que a partir de consultas a bases de dados sobre pesquisas acerca do Plantão Psicológico no Brasil, há poucos estudos referindo-se à vivência dos clientes que receberam esse tipo de intervenção psicológica, principalmente em um Hospital Geral, o que aponta a relevância deste estudo.

Atualmente, os psicólogos clínicos têm se defrontado com novas questões quando trabalham em instituições e têm procurado redefinir a concepção de Psicologia Clínica para responder às novas demandas (Tassinari, 2003). Insere-se aqui uma tomada de posição mais ampla sobre a concepção de atendimento clínico, libertando-o do viés tradicional, em que a Psicoterapia era a única via possível para a atenção psicológica e longos processos terapêuticos eram sinônimos de tratamentos eficazes (Cury, 1999a).

Em contraponto a uma visão tradicional de Psicologia Clínica, que se sustenta numa análise estrutural da personalidade humana, ressaltando aspectos psicopatológicos do indivíduo, emerge uma clínica mais abrangente, respondendo a uma necessidade da comunidade em seu viver cotidiano. Sua atuação tem como base a concepção preventiva, e esse novo enfoque exige uma ampla reflexão teórica, para melhor instrumentalizar uma prática mais efetiva (Pereira, 1999).

O Plantão Psicológico apresenta-se, então, como uma nova modalidade de atendimento clínico criado a partir da atenção à centralidade da pessoa. Esta prática clínica surgiu da importância de se ter um espaço para as pessoas, muito mais dos que para os problemas promovendo, assim, a consciência de si e da realidade, levando a pessoa a discriminar os diferentes recursos disponíveis (Mahfoud, 1987).

Este tipo de atendimento também foi criado como forma de solucionar a grande demanda de clientes à espera de atendimento psicológico em instituições públicas e privadas, uma vez que muitas vezes estas pessoas podem beneficiar-se de um único encontro com um psicólogo, não necessitando da psicoterapia.

O Plantão Psicológico, enfatiza Rosenberg (1987), não tem a intenção de substituir a psicoterapia e propõe cada atendimento como um universo único, ou seja, como um atendimento característico da Abordagem Centrada no Cliente, que tem como premissa a confiança no organismo para avaliar as situações externas e internas, compreender a si mesmo no seu contexto e fazer escolhas construtivas para sua vida.
Pereira (1999) sustenta que o Plantão Psicológico responde à demanda imediata do cliente, tanto em termos temporais quanto em relação a suas necessidades emocionais; esse tipo de atendimento numa instituição acarreta agilidade frente à comunidade e possibilita ao plantonista o desenvolvimento de uma forma especifica de atendimento institucional.

Para Amatuzzi (1990), o objetivo do Plantão Psicológico consiste em propiciar a facilitação de um processo que é do cliente e, portanto, a função do plantonista é acompanhar esse processo, e não conduzí-lo. Cury (1999a) complementa caracterizando o atendimento de Plantão Psicológico como sendo de caráter emergencial e privilegiando a demanda emocional imediata e espontânea do cliente.

Partindo do pressuposto de que uma instituição está bem quando os membros que a compõem estão bem, Cautella (1999a) afirma que se faz necessário, em algum momento da história de uma instituição hospitalar, instaurar um espaço de acolhimento e segurança para seus funcionários. A estrutura do Plantão Psicológico responde a essa demanda institucional, na qual o funcionário tem um espaço para expressar suas angústias, seus anseios e estruturarse melhor para dar conta das exigências internas e do seu cotidiano neste contexto de trabalho.

Pucci (1999) relata que, nas instituições de Saúde, como os hospitais, verifica-se a necessidade de cuidar-se dos profissionais, para o benefício destes e para a qualidade de trabalho oferecido àqueles que estão doentes e necessitam de cuidados especiais. Isso em função de algumas dificuldades específicas, tais como insatisfação no trabalho, baixa utilização das potencialidades, rotina, inadequação das condições de trabalho, que podem levar a conseqüências como absenteísmos, diminuição no rendimento e um aumento de reclamações, causando sérias conseqüências na saúde física e mental dos funcionários.

Cautella (1999a) afirma ainda que, para a implantação do Plantão Psicológico em um Hospital, é necessário que se acredite na capacidade de sua clientela para desenvolver-se. É preciso também que o serviço seja sistematizado, para que o cliente saiba quando e onde o plantonista estará à disposição; este deve preparar-se para situações inesperadas, pois irá confrontar-se com o não planejado e ambos devem estar cientes da possibilidade de ser um encontro único, o que exige uma maior sensibilidade frente às questões do cliente.

Para que um Serviço de Plantão Psicológico se constitua como tal, a instituição deve garantir a presença de psicólogos em lugar e horários pré-determinados. Assim, o cliente poderá usar o atendimento psicológico como espaço de acolhimento e referência no momento em que sentir necessidade (Morato, 1997).

Cury (1999a) apresenta como resultado de pesquisa que o Plantão Psicológico representa uma flexibilização quanto às formas de atendimento clínico oferecidas à população, promovendo também uma economia para o sistema, na medida em que promove encaminhamentos internos e externos. Afirma esta autora que o psicólogo-plantonista deve 
responsabilizar-se pela forma como as diversas instituições compreendem e inserem o serviço de Plantão Psicológico, mantendo uma percepção clara acerca da ideologia subjacente ao atendimento e impedindo que esta prática sirva a propósitos outros decorrentes da política institucional.

Deve-se impedir que se imprima um caráter amadorístico e sem embasamento teórico ao processo de implantação desta prática, beneficiando apenas às necessidades financeiras da instituição. Esse risco está em vincularmos a quantificação dos atendimentos à eficiência do modelo institucional (Cury, 1999b).

\section{Objetivo}

Avaliar a efetividade do Plantão Psicológico disponibilizado aos funcionários de um Hospital Geral, a partir dos relatos das vivências dos próprios funcionários atendidos neste Serviço.

\section{Método}

O caminho metodológico escolhido para investigar as vivências dos funcionários de um hospital geral, quando lhes foi disponibilizado um Serviço de Plantão Psicológico foi a análise fenomenológica dos relatos das vivências fornecidos pelos próprios funcionários. Especificamente, nos detivemos naqueles funcionários que haviam sido atendidos durante a fase de implantação do referido Serviço.

O termo fenomenologia psicológica refere-se à fenomenologia como um método aplicado aos problemas de natureza psicológica, ou utilizado a um nível psicológico de questionamento. Consiste num processo específico para abordar a consciência e a experiência humana imediata. Pode ser definido como um tipo de observação sistemática e de descrição da experiência de um indivíduo consciente, numa dada situação (Cury, 1987, p. 43).

\section{Contexto onde foi Desenvolvida a Pesquisa}

O Hospital Geral no qual se implantou o Serviço de Plantão Psicológico é uma instituição privada; a maior parte dos seus clientes são conveniados e uma menor parcela é de clientes particulares.

Para efetuar-se a implantação do Serviço neste Hospital foi necessário que o projeto fosse submetido à aprovação da diretoria do Hospital; após essa etapa, foi destinada uma pequena sala temporária às plantonistas e, após três meses, o Serviço de Plantão Psicológico mudou-se para outra sala maior e mais adequada, na qual duas plantonistas permaneciam de plantão todas as quintas-feiras e sextasfeiras, das 9 h3o às $17 \mathrm{~h} 30$.

Para a divulgação do Serviço, foi feita uma reunião com a equipe de chefia para explicar e esclarecer suas finalidades, objetivos e procedimento de implantação, com o intuito de que eles incentivassem os membros de suas equipes a procurar pelo Serviço quando sentissem necessidade; também foram fixados cartazes nos murais do Hospital e distribuídos panfletos explicativos aos funcionários pelas próprias plantonistas para melhor repercussão e esclarecimentos.

O Serviço de Plantão Psicológico foi destinado aos funcionários do Hospital - corpo clínico e funcionários, contratados ou terceirizados. Antes de este Serviço ser oferecido, os funcionários eram assistidos por duas psicólogas que os atendiam segundo suas queixas, ou seja, a psicóloga da área de Recursos Humanos do hospital acolhia os funcionários cujas queixas eram relacionadas a problemas do âmbito profissional, enquanto a psicóloga da área clínica (hospitalar) acolhia os funcionários cujas queixas decorressem de problemas pessoais ou familiares.

A atenção desenvolvida pelas psicólogas responsáveis pela implantação do Serviço de Plantão Psicológico é de caráter clínico, assim como as atividades já desenvolvidas pela psicóloga hospitalar, responsável pela demanda do ambulatório e das alas do hospital (leitos da enfermaria, apartamento, maternidade, pediatria e Unidade de Tratamento Intensivo - U.T.I.). No entanto, o Serviço de Plantão Psicológico é direcionado para os funcionários do hospital, enquanto o trabalho da psicóloga hospitalar é direcionado aos pacientes. Já o trabalho da psicóloga da área de Recursos Humanos é de natureza organizacional, com suas atividades voltadas para o desenvolvimento e crescimento dos funcionários e da empresa de forma mais direta.

O projeto começou apenas com o Serviço de Plantão Psicológico, sendo procurado pelos funcionários como forma de alívio em relação a ansiedade e angústia imediatas e também como um espaço que proporciona reflexão sobre seus questionamentos e problemas. Com a solicitação de alguns funcionários para que se fizesse um atendimento psicológico a algum familiar seu, foi concedida, quando necessário, a mesma modalidade de atendimento psicológico ao filho, cônjuge ou pais.

No entanto, alguns dos clientes sentiram necessidade de cuidar de questões de ordem psicológica despertadas durante o atendimento de Plantão Psicológico. Então, o Serviço oferecido aos funcionários ampliou-se e passou a chamar-se «Serviço de Atenção Psicológica destinado aos colaboradores»» e está dividido em duas modalidades de atendimento: Plantão Psicológico e Psicoterapia. Ainda assim, ressalta-se que a grande demanda permanece em relação ao atendimento de Plantão Psicológico.

\section{Participantes da Pesquisa}

Esta pesquisa contou com a participação de seis funcionários, dois do sexo masculino e quatro do sexo feminino, que foram atendidos pelo Serviço de Plantão Psicológico, disponibilizado a eles no próprio ambiente de trabalho, no período compreendido entre março e setembro de 2004. Este número resultou da aplicação do critério de saturação,

Foram gravados os depoimentos daqueles colaboradores que se dispuseram e consentiram em participar da pesquisa, após terem sido suficientemente informados sobre os objetivos da mesma.

Entrevista Não-Diretiva: Optou-se por uma modalidade de entrevista denominada de entrevista não-diretiva. A 
entrevista não diretiva, como técnica qualitativa de coleta de dados, é o inverso do questionário que se baseia em perguntas. A entrevista é aqui "aberta” e "centrada”, quer dizer, ela se baseia não nas reações do entrevistado a perguntas precisas, mas na expressão livre de suas idéias sobre um assunto. Para um entrevistador, ser "não diretivo" é querer não impor nada ao entrevistado, mas obter dele expressões espontâneas, absolutamente não devidas a induções vindas da situação do encontro ou de suas próprias atitudes, comportamentos e reações no momento deste encontro (Mucchielli, 1991, p. 28).

Nesta pesquisa foi feita uma pergunta disparadora, a partir da qual o participante é estimulado a discorrer livremente sobre um tema que constitui o foco de pesquisa, sendo feitas pequenas intervenções visando esclarecimentos necessários. A questão disparadora foi a seguinte:

"Estou pesquisando o Plantão Psicológico e gostaria que você me ajudasse contando como foi para você este tipo de atendimento".

\section{Procedimentos}

A pesquisadora entrou em contato com os funcionários do Hospital que haviam sido atendidos no Serviço de Plantão Psicológico e consultou-os sobre o interesse em participar da pesquisa, explicando-lhes acerca dos objetivos da mesma.

Os colaboradores que concordaram em participar da pesquisa tiveram suas dúvidas esclarecidas e foram devidamente informados de que a sua participação seria voluntária, sob a forma de depoimentos gravados. Dados pessoais que pudessem levar à identificação dos participantes foram omitidos.

Para estes que manifestaram interesse, foi agendado um segundo encontro, no qual houve a leitura e assinatura do Termo de Consentimento Livre e Esclarecido e ocorreram as entrevistas propriamente ditas, as quais foram gravadas, com o consentimento de cada participante, e transcritas posteriormente. Na seqüência, a pesquisadora solicitou outro encontro para que cada par ticipante lesse o texto referente à transcrição do seu depoimento para eventuais correções ou esclarecimentos que julgasse necessários.

As entrevistas foram realizadas nas dependências do próprio Hospital Geral, na sala destinada aos atendimentos do Serviço de Atenção Psicológica aos funcionários, com exceção de uma participante que preferiu ser entrevistada na sala onde desempenha suas funções profissionais.

\section{Análise dos Depoimentos}

A partir da proposta de Amatuzzi (2001), a análise dos depoimentos deste estudo foi efetivada por meio dos seguintes passos:

1. Os depoimentos gravados foram transcritos, tendo sido efetivada uma literalização de forma a obter uma adequação gramatical. O texto do primeiro depoimento foi dividido em unidades de significado.

2. Elaborou-se a compreensão psicológica destas unidades de significado e a construção da síntese específica deste depoimento.
3. A seguir elaborou-se a compreensão psicológica de cada depoimento e a síntese específica do mesmo, comparando-se à síntese específica do depoimento anterior; procedeu-se desta forma, sucessivamente, até alcançar-se o ponto de saturação, ou seja, a partir do qual a pesquisadora não encontrou nenhum elemento novo, inédito, em relação à análise dos depoimentos anteriores.

4. Finalmente, efetivou-se uma Síntese Geral, construída como uma apreensão dos elementos do vivido considerados como elementos invariantes presentes no conjunto de todos os depoimentos.

A fim de exemplificar os passos descritos seguidos pela pesquisadora segue a análise de um dos depoimentos:

Depoimento VI dividido em Unidades de Significado (US) e Compreensão Psicológica (CP) da pesquisadora:

$\mathrm{CP} 1$ : Sente que foi muito bem recebida nas duas vezes em que precisou do Plantão Psicológico.

US1:

"Para mim foi excelente, em todos os momentos que precisei deste atendimento fui muito bem atendida..." $\mathrm{CP}_{2}$ : Sente que o atendimento de Plantão Psicológico ajudou-a resolver tanto questões pessoais como questões profissionais, porque pôde compreender melhor as situações vivenciadas e a ajuda é prática e rápida. US2:

. . . não só nas questões profissionais e de relacionamentos pessoais entre colegas de trabalho, mas até por questões pessoais ou de vivências com clientes vocês realmente me auxiliam muito em entender essas questões e sair até com as questões resolvidas, entre aspas.

. . . são questões práticas que no dia-a-dia você gostaria de estar dividindo com seu colega de trabalho, pra poder solucionar da melhor forma. Nas questões principalmente pessoais dentro dos relacionamentos profissionais foi extremamente útil, aonde consegui clarear conversando com vocês as questões e encontrar até saídas que eu não estava vendo; e é bem prático, bem rápido.

CP3: Sente-se acolhida, sem ser julgada, durante os atendimentos de Plantão Psicológico, e segura quanto ao sigilo das conversas.

US3:

"É um momento em que a gente se sente acolhida, sem julgamentos, tendo a certeza de que vai ficar entre nós, neste quarto, onde a gente está sendo atendida."

CP4: Gostaria que o Serviço continuasse e se dispõe a contribuir para dar continuidade a ele, pois acredita que beneficiará muito os funcionários do Hospital.

US4:

"Então, pra mim foi excelente, eu gostaria até que continuasse, se depender de incentivos, de divulgar esse trabalho, pra nós funcionários do Hospital vai ser maravilhoso."

CP5: O fato de o Plantão acontecer no próprio ambiente de trabalho é muito positivo, pois possibilita o 
atendimento em momentos de urgência como no dia em que entrou chorando na sala de Plantão, devido a problemas de relacionamento no próprio trabalho.

US5:

Melhor ainda, eu acho que exatamente por isso eu falei, a gente tem tanto conflito, entre os próprios colegas de trabalho mesmo que às vezes você acha que não tem solução, você está desesperada; quantas vezes eu entrei na sua sala chorando, nervosa, não vendo saída e que vocês me clarearam e que depois num bate-papo, numa conversa, lógica que tem o lado profissional de vocês, a gente conseguiu clarear para que eu pudesse resolver aqui fora.

Síntese Específica de Giovana: Giovana vivenciou o atendimento de Plantão Psicológico no próprio ambiente de trabalho como importante, sentindo-se aceita, acolhida, sem sentir-se julgada e com total confiança quanto ao sigilo das conversas. Percebeu a importância de ter sido atendida no momento em que surgiu a necessidade, num momento de desespero por problemas no trabalho. Sente que o atendimento ajudou-a a pensar sobre as situações pelas quais estava passando e a resolver certas questões pessoais e profissionais, de forma rápida e prática. Colocou-se à disposição para ajudar no que for necessário para que o Serviço de Plantão Psicológico seja mantido no Hospital, pois acredita que beneficiará muitos outros funcionários além dela própria.

Sintese Geral obtida a partir dos Depoimentos dos seis Participantes, Indicando como Apreenderam ou Vivenciaram o Atendimento de Plantão Psicológico:

1. PP no próprio ambiente de trabalho avaliado como uma experiência positiva.

2. Possibilita alívio para angústias e momentos de reflexão.

3. Busca de novos caminhos - em nível pessoal e profissional.

4. Espaço de escuta verdadeira, acolhimento e confiança.

5. PP reconhecido como um cuidado da instituição em relação aos funcionários.

6. Indicam aos colegas este tipo de ajuda.

7. Apontam que deveria ser mais divulgado.

8. Prontificam-se a ajudar na manutenção do Serviço.

9. Sugerem desvinculação do Serviço PP do Setor de RH do Hospital - funções distintas e complementares.

10. Escuta do plantonista é acolhedora, isenta e incondicional.

11. Distinguem ajuda médica da psicológica oferecida no PP.

12. PP proporciona apoio, escuta diferenciada e segurança quanto ao sigilo perante superiores e colegas.

13. Hospital também se beneficia porque sentem que o atendimento de PP promove melhoria na qualidade de vida e melhor desempenho profissional.

14. Gostariam que outros funcionários se beneficiassem deste tipo de atendimento - acreditam que os chefes de setor deveriam incentivar seus funcionários quando necessário.
15. PP como ajuda que chega em momentos difíceis do cotidiano.

16. Mencionam que este tipo de Serviço já existe em outros Hospitais e Empresas, valorizando a manutenção desta prática psicológica.

\section{Resultados e Discussão}

Sob uma perspectiva social, o Plantão Psicológico apresenta-se como uma alternativa às intervenções clínicas tradicionais, tendo emergido a partir de uma percepção da necessidade de ampliação dos serviços disponibilizados à população e, ainda, como um questionamento em relação aos modelos padronizados de atenção psicológica vigentes nas instituições de saúde.

A proposta de compreender a afetividade da modalidade de Plantão Psicológico quando aplicada ao contexto de um Hospital Geral a partir da vivência dos clientes, que neste caso foram os próprios funcionários, conseguiu abarcar uma compreensão acerca de elementos psicológicos presentes na relação plantonista-cliente e também um breve vislumbrar sobre a relação cliente-instituição, possibilitando uma análise quanto ao âmbito do próprio campo em estudo.

O conceito de emergência emocional neste estudo tem como pressuposto uma consideração em relação à existência de elementos subjetivos em cada pessoa que procura por ajuda psicológica. Augras (1978) afirma que existe uma "cronologia existencial" nas relações do homem com o mundo, sendo a vivência do tempo algo particular, ou seja, questões como o tempo e o espaço se afirmam como dimensões significativas do ser. No Plantão Psicológico, em especial, estas dimensões parecem fundidas na questão da emergência emocional de cada um, isto é, para alguns a emergência pode ser uma discussão com o namorado, enquanto para outro é a eminente tentativa de suicídio.

Cabe ao cliente a delimitação sobre qual é a sua emergência existencial e como os participantes desta pesquisa apontaram, cabe também ao plantonista acolher e compreender este momento especial no qual o cliente quer refletir com alguém sobre alguma questão pessoal que o inquieta.

Como esperado, o tempo foi vivido subjetivamente pelos clientes nos atendimentos de Plantão neste Hospital, pois para alguns um único plantão foi suficiente e para outros foram necessários dois retornos; no entanto, de forma geral, o Plantão Psicológico proporcionou uma maior abertura e receptividade por parte do cliente para vivenciar suas questões emocionais e seus sentimentos emergentes. Isto se deu principalmente, pelo fato de o cliente procurar espontaneamente por ajuda psicológica na hora em que sentiu que esta poderia ajudá-lo a refletir sobre questões que o afligiam.

Bartz (1997) afirma que o Plantão Psicológico é uma nova tendência da Psicologia Clínica voltada ao atendimento de emergências, e que funciona como instância confirmatória da importância, do valor e da utilidade para aqueles que procuram por este tipo de atendimento. Este 
Serviço implantado no Hospital Geral revelou-se de acordo com essa afirmação, trazendo também a complementação de que esta modalidade, segundo a vivência dos usuários, não se propõe a ajudar apenas nessas "situações emergenciais", mas é percebida por eles como um atendimento capaz de oferecer mais do que isso. O participante João indica isto ao dizer que recorre ao Plantão Psicológico sempre que sente necessidade de cuidar principalmente de questões de ordem profissional, pois sente que, como chefe de setor, a demanda que recai sobre ele é grande.

Mahfoud (1987) afirma, a partir da experiência da implantação de um Serviço de Plantão Psicológico no contexto escolar voltado aos alunos, que este Serviço "vagarosamente foi se instalando como um espaço para as pessoas, mais do que para os problemas" (p. 38). Essa experiência de Plantão no contexto escolar evidenciou-se como um agente de promoção da saúde e de atenção cuidadosa aos alunos em seu cotidiano escolar, assim como o Plantão Psicológico no contexto hospitalar foi vivido pelos funcionários com uma função semelhante em relação ao cotidiano de trabalho na instituição.

Faz-se oportuno apontar que os resultados desta pesquisa mostraram-se semelhantes, em alguns aspectos, àqueles descritos por Tassinari (2003), no que concerne ao fato de os usuários de uma Clínica-Escola procurarem pelo Serviço de Plantão Psicológico não apenas em situações de emergência, mas também com o propósito de conhecer a proposta, de cumprimentar ou avisar que voltarão depois, aparecendo sem saber exatamente para quê ou, quem sabe, apenas para compartilhar seus dramas pessoais, suas inquietações face a outra pessoa, permitindo-se emocionar-se sem constrangimentos.

Diferentemente da pesquisa de Messias (2002), que evidenciou que a maior parte das pessoas que procuram pelo Plantão nas Clínicas-Escolas traz queixas orgânicas ou foi encaminhada por médicos, os clientes do Plantão Psicológico neste Hospital Geral, a despeito de estarem inseridos num Hospital, procuraram por este tipo de atendimento espontaneamente e sem encaminhamento médico. Isto evidencia que estes funcionários diferenciam a ajuda médica da psicológica e souberam apreender a natureza da ajuda que o Plantão Psicológico pode oferecer, ou seja, o âmbito de ajuda neste Serviço é estritamente psicológico e não serve como paliativo ao sofrimento físico. Larissa manifestou-se a este respeito da seguinte forma:

. . . foi a primeira experiência dentro do Hospital da gente dessa forma, o socorro chegou até a gente, está mais próximo, fora essa área de pronto socorro, mas assim, da parte psicológica foi a primeira vez que veio tão perto ... Aqui é o único setor que oferece ajuda ao funcionário dentro do Hospital além da ajuda médica, da medicina grossa que cuida da dor de barriga, soro etc, mas esta não oferece apoio. (Participante I).

A pesquisa desenvolvida por Messias (2002) mostrou ainda que as atitudes percebidas pelos clientes definidas como calma, acolhimento e aceitação por parte da plantonista foram consideradas muito importantes para que a relação de ajuda psicológica se efetivasse. Já na presente pesquisa, os participantes destacaram como mais significativas atitudes definidas por eles como sigilo e isenção por parte dos plantonistas. O excerto seguinte exemplifica este ponto:

"É um momento em que a gente se sente acolhida, sem julgamentos, tendo a certeza de que vai ficar entre nós, neste quarto, onde a gente está sendo atendida" (Participante VI).

Nos plantões psicológicos prioriza-se a compreensão do cliente em sua dimensão total como pessoa, considerando-o na sua expressão tanto de sentimentos e emoções como de comportamentos e atitudes, com o objetivo de ajudá-lo a significar, refletir e encontrar novos caminhos diante do que está vivenciando no momento em que procura pelo atendimento psicológico. Compreende-se que o atendimento foi terapêutico quando o cliente pode sentirse livre para expressar-se ou recolher-se, para que ele possa ao longo deste processo reconhecer os conteúdos emocionais que está vivenciando e reconfigurar sua problemática, transformando seu sofrimento ou dificuldade numa reflexão em relação a novas possibilidades do viver a partir deste encontro.

O funcionamento do Serviço de Plantão Psicológico neste Hospital Geral teve como referencial o padrão já existente a partir da implantação deste tipo de Serviço em outros contextos e a função exercida também foi a de acolher, compreender, esclarecer, refletir, orientar, e, em alguns casos, encaminhar. No entanto, para os funcionários deste Hospital também foi atribuída ao Serviço a função de pensar junto, de ter um refúgio em momento de dificuldade profissional para organizar idéias e tomar alguma atitude e ainda, a de oferecer segurança emocional, pelo fato de saberem que, se precisarem de ajuda psicológica, eles dispõem de um serviço à disposição para esta finalidade.

Moreira (2002) buscou entender as possibilidades do Plantão Psicológico em um ambulatório de Saúde Mental, com pacientes egressos de primeira internação psiquiátrica. Concluiu que o Plantão Psicológico funcionou como forma de acolhimento afetivo e escuta empática, além de promover um diálogo atento às vivências emocionais no momento em que estes pacientes buscavam algum tipo de ajuda. Isso evidencia que, a despeito dos diferentes contextos e públicos ao qual se destinou o Serviço de Plantão Psicológico, a forma como os usuários o compreenderam foram similares.

Ressalta-se, ainda, que as dificuldades encontradas pelas plantonistas durante a fase de implantação do Serviço de Plantão Psicológico neste hospital decorreram do delicado processo de conquistar a confiança dos funcionários e pela dificuldade de divulgar o Serviço ao Hospital como um todo, considerando-se a grande demanda de funcionários, distribuídos em vários turnos. Em relação à primeira questão, esta foi superada; já em relação à divulgação, evidenciou-se que não foi completa, segundo os trechos a seguir dos depoentes:

"porque precisa ser anunciado" (Partipante II).

“. . . só que precisaria divulgar mais" (Participante I). 
Diante dos resultados obtidos, evidenciando uma melhora na qualidade de vida do funcionário após o atendimento no Plantão, cabe citar Pucci (1999), que afirma que nas instituições de Saúde, como Hospitais, verifica-se a necessidade de cuidar dos profissionais, para o beneficio destes e para a qualidade de trabalho oferecido àqueles que estão doentes e necessitam de cuidados especiais.

As atitudes facilitadoras dos plantonistas e o acolhimento percebido pelos funcionários, permitiram a valorização da queixa subjetiva de cada funcionário, de forma a propiciar uma mudança de perspectiva e de atitude, levando o cliente a uma maior autonomia e poder sobre elas. Rogers (1995) propôs a existência de três atitudes que ao serem vividas subjetivamente pelo terapeuta e adequadamente comunicadas ao cliente durante as sessões, promovem a facilitação das relações interpessoais: aceitação positiva incondicional, empatia e autenticidade. Os resultados desta pesquisa evidenciaram a importância destas atitudes também para os plantonistas.

Cautella (1999b) relata que a implantação de um Serviço de Plantão Psicológico em um Hospital Psiquiátrico contribuiu para que a instituição reformulasse a sua postura frente à doença mental. Após três anos de funcionamento, ampliou-se este Plantão aos familiares e ainda aos funcionários do Hospital; no entanto, esta função foi exercida por um profissional externo a esta Instituição.

Nesta pesquisa, também revelou-se a necessidade de o Serviço de Plantão Psicológico ser desvinculado do setor de Recursos Humanos da empresa, pois sentem os participantes que, a despeito de ambos os setores preocuparem-se com o bem-estar no Hospital, trata-se de funções distintas. Assim como explicita Larissa:

. . . Só que não são as psicólogas que contratam aqui no hospital, porque não podem ser, elas já tem um outro relacionamento de trabalho com você, ela te contratou pela sua capacidade, pela sua formação, pela sua experiência, então é outro relacionamento que você tem com ela, ela não te vê com esses olhos . . . (Partipante I).

Outro ponto a ser destacado é a importância atribuída à ajuda psicológica recebida no momento em que a emergência se fez presente; os participantes consideram positivo o fato de o Serviço de Plantão Psicológico estar inserido no próprio ambiente de trabalho.

Segundo os resultados desta pesquisa, pode-se concluir que os funcionários do Hospital Geral compreenderam os objetivos do Serviço de Plantão Psicológico a eles disponibilizado, pois o Serviço tornou-se um referencial de ajuda psicológica; os funcionários apreenderam a natureza emergencial dessa ajuda, recorrendo a ela em momentos difíceis, tanto no âmbito pessoal como no cotidiano profissional, diferenciando-a da ajuda médica que eles também recebem. Percebem ainda o Plantão com a função de oferecer-lhes segurança, por terem psicólogas à disposição, caso precisem, e também porque as plantonistas parecem garantir-lhes um clima de sigilo, ainda que estejam no ambiente profissional.
Diante dos dados descritos, conclui-se que o Serviço de Plantão Psicológico destinado aos funcionários alcançou uma repercussão positiva dentro do Hospital. A despeito do cur to período transcorrido desde a implantação do Serviço de Plantão Psicológico no Hospital, a experiência dos funcionários acerca desta modalidade de prática clínica evidencia sua importância pelo desejo expresso nos depoimentos de que seja mantida sua continuidade para o bem estar, não só daqueles que dele se beneficiam, como também para uma melhoria na qualidade das relações interpessoais vividas no cotidiano da instituição.

Os resultados deste estudo apontam caminhos otimistas para futuros estudos acerca da modalidade clínica de Plantão Psicológico, não só para o contexto hospitalar, como também para outros contextos. As dificuldades enfrentadas no início da implantação pelas psicólogas-plantonistas foram superadas e alcançou-se um espaço no qual os funcionários podem desfrutar de um cuidado psicológico especialmente destinado a eles.

Conclui-se também que a proposta deste Serviço de Atenção Psicológica voltado aos funcionários de um Hospital acompanhou os pressupostos teóricos e práticos de outros estudos anteriormente realizados, enfatizando-se que os pilares do Humanismo guiaram esta pesquisaintervenção, por meio da noção de respeito ao outro, autenticidade, liberdade de pensamento, possibilidade de escolha e possibilidade de encontro. Levou-se em consideração a capacidade unicamente humana de intencionalmente pensar o mundo e as relações por meio de uma consciência reflexiva.

\section{Conclusões}

Esta pesquisa-intervenção propôs-se, em princípio, a produzir um conhecimento científico baseado na ética e na intenção de promover melhores condições na qualidade de vida dos funcionários de um Hospital Geral. Ao concluir esta Dissertação de Mestrado, a pesquisadora buscou trazer à luz e refletir acerca de questões que possam contribuir para o exercício de uma prática psicológica clínica legítima e com a possibilidade de complementar outros estudos científicos já feitos sobre este tema.

A experiência de constituir-se como pesquisadora num tipo de estudo como este de pesquisa/intervenção permitiu que o projeto da Dissertação de Mestrado ampliasse a prática profissional, levando a um aprendizado rico do modo de produção do conhecimento científico e, ao mesmo tempo, a uma contribuição para a qualidade de vida das pessoas envolvidas. Surpreendeu o fato de os dados da pesquisa adquirirem vida própria, isto é, embora houvesse um foco a conduzir as conversas com os funcionários, estes ampliaram-no imprimindo-lhe novos significados.

A análise da efetividade de um Serviço de Plantão Psicológico quando aplicada em um Hospital Geral, segundo a vivência e perspectiva dos próprios usuários, parece apontar que ainda existe a necessidade de outras pesquisas e empreendimentos para a consolidação de uma linha de 
pesquisa voltada às práticas psicológica clínicas em Instituições.

O Plantão Psicológico é uma modalidade que está sendo exaustivamente submetida à investigação científica, para que se possa viabilizar a compreensão e interpretação de todos os elementos de ordem psicológica pertinentes à geração de novas hipóteses teóricas a consolidar a área da atenção psicológica clínica. No entanto, por mais profunda e fidedigna que seja a investigação científica, não se pode ter a pretensão de descobrir uma verdade absoluta e permanente, pois isto jamais seria possível pela própria natureza do fenômeno humano.

\section{Referências}

Amatuzzi, M. M. (1990, ago./dez.). Que é ouvir. Estudos de Psicologia, 7(2), 86-97.

Amatuzzi, M. M (2001). Pesquisa fenomenológica em Psicologia. In M. A. T. Bruns \& A. F. Holanda. Psicologia e pesquisa fenomenológica: Reflexões e perspectivas (pp. 35-56). São Paulo, SP: Ômega.

Augras, M. (1978). O ser da compreensão: Fenomenologia da situação de diagnóstico. Petrópolis, RJ: Vozes.

Bartz, S. S. (1997, jan./jul.). Plantão psicológico: Atendimento criativo à demanda de emergência. Interações, 2(3).

Cautella, W. J. (1999a). Plantão psicológico em hospital psiquiátrico. In H. T. P. Moratto (Ed.), Aconselhamento psicológico centrado na pessoa (pp. 159- 173). São Paulo, SP: Casa do Psicólogo.

Cautella, W. J. (1999b). Plantão psicológico em hospital psiquiátrico: Novas considerações e desenvolvimento. In M. Mahfoud (Ed.), Plantão psicológico: Novos horizontes (pp. 97114). São Paulo, SP: Companhia Ilimitada.

Cury, V. E. (1987). Psicoterapia centrada na pessoa: Evolução das formulações sobre a relação terepeuta-cliente. Dissertação de Mestrado não-publicada, Universidade de São Paulo, SP.

Cury, V. E. (1999a). Plantão psicológico em clínica-escola. In M. Mahfoud (Ed.), Plantão psicológico: Novos horizontes (pp. 120135). São Paulo, SP: Companhia Ilimitada.

Cury, V. E. (1999b). Psicólogos de plantão... In M. Mahfoud (Ed.), Plantão psicológico: Novos horizontes (pp. 135-138). São Paulo, SP: Companhia Ilimitada.

Dyck, R. J., \& Azim, H. F. (1983, Feb.). Patient satisfaction in a Psychiatric Walk-in Clinic. Canadian Journal of Psychiatry, $28(1)$.

Eisenlohr, M. G. V. (1997). Formação de alunos em psicologia: Uma possibilidade para educadores. Dissertação de Mestrado nãopublicada, Instituto de Psicologia, Universidade de São Paulo, SP.

Mahfoud, M. (1987). A vivência de um desafio: Plantão psicológico. In R. L. Rosenberg (Ed.), Aconselhamento psicológico centrado na pessoa (pp. 75- 83). São Paulo, SP: EPU.

Messias, T. S. C. (2002). Plantão psicológico como possibilidade de facilitação de tendência atualizante: Um estudo clínico. Dissertação de Mestrado não-publicada, Pontifícia Universidade Católica de Campinas, SP.

Morato, H. T. P. (1997, jan./jun.). Experiências do serviço de aconselhamento psicológico do IPUSP: Aprendizagem significativa em ação. Boletim de Psicologia, 47(106).

Moreira, E. N. (2002). Plantão psicológico em ambulatório de saúde mental: Um estudo fenomenológico. Disser tação de Mestrado nãopublicada, Pontifícia Universidade Católica de Campinas, SP.
Mucchielli, A. (1991). Lês mèthodes qualitatives. Paris: PUF.

Pereira, P. C. (1999). A entrevista única: Uma nova modalidade de atendimento na psicologia clinica. Disser tação de Mestrado nãopublicada, Pontifícia Universidade de Campinas, SP.

Pucci, F. F. (1999). Profissionais de saúde: Análise de algumas variáveis que influem no trabalho em UTI. Disser tação de Mestrado não-publicada, Pontifícia Universidade Católica de Campinas, SP.

Rogers, C. R. (1995). As condições necessárias e suficientes para a mudança terapêutica de personalidade. In J. K. Wood (Ed.), Abordagem centrada na pessoa (2. ed.). Vitória, ES: Editora da Fundação Ceciliano Abel de Almeida.

Rosenberg, R. L. (1987). Aconselhamento psicológico centrado na pessoa. São Paulo, SP: EPU.

Tassinari, M. (2003). A clínica da urgência psicológica: Contribuições da ACP e da teoria do caos. Tese de Doutorado nãopublicada, Universidade Federal do Rio de Janeiro, RJ.
Recebido: 16/08/2006 $1^{a}$ revisão: $24 / 01 / 2007$ Aceite final: 05/03/2007 